\title{
Diferentes faces da depressão no suicídio em idosos
}

\section{Different aspects of depression in suicide among the elderly}

Fátima Gonçalves Cavalcante ${ }^{1}$

Maria Cecília de Souza Minayo ${ }^{1}$

Raimunda Matilde do Nascimento Mangas ${ }^{1}$

${ }^{1}$ Centro Latino Americano de Estudos de Violência e Saúde Jorge Carelli. Escola Nacional de Saúde Pública. Fiocruz. Av. Brasil 4036/700, Manguinhos. 21.040-361 Rio de Janeiro RJ.

fatimagold7x7@yahoo.com.br
Abstract This article analyzes different aspects of depression association with suicide among the elderly based on psychological autopsies. The retrospective method was used to study indeterminate deaths, based on interviews and reports, which analyze psychosocial circumstances related to suicide. The paper reveals the predominance of gender, social class and race - women, middle and upper class, white - and, in an unprecedented manner, contextualizes depression in a poorly studied population in Brazil and in the world with high risk of suicide. The physical and mental health, social circumstances and predominant biographical characteristics of the suicide victim were reconstructed in order to assess the impact of depression on suicide. Depression was presented in almost all cases, in primary or secondary diagnosis, as the symptom associated with other co-morbidities or as a reaction to social stressors, demanding different therapeutic approaches and procedures. The association between depression and multiple co-morbidity accentuates the case prognosis and cumulatively increases the risk of suicide. Depression followed by suicidal tendencies is a risk factor which justifies immediate preventive measures. Increasing assertive ways to diagnose and treat depression in old age is recommended.

Key words Suicide among the elderly, Depression, Psychological autopsy
Resumo $O$ artigo analisa diferentes faces da depressão associadas a suicídio em idosos, a partir de autópsias psicológicas. Utilizou-se um método retrospectivo para o estudo de mortes indeterminadas, a partir de entrevistas e laudos, que analisa circunstâncias psicossociais associadas ao suicídio. O artigo traz uma predominância de gênero, classe social e raça - mulheres, classe média e alta, brancos - e contextualiza de modo inédito a depressão numa população de alto risco de suicídio, pouco estudada no Brasil e no mundo. Buscou-se reconstituir o nível de saúde física e mental, as circunstâncias sociais e os traços biográficos marcantes para compreender a magnitude da depressão no suicídio. A depressão apareceu na quase totalidade dos casos como diagnóstico primário ou secundário, como sintoma associado a outras comorbidades ou como reação a estressores sociais, demandando diferentes condutas e procedimentos terapêuticos. A associação entre depressão e comorbidade múltipla agrava o prognóstico do caso e amplia cumulativamente o risco de suicídio. A depressão acompanhada de ideações suicidas é um fator de risco que justifica medidas preventivas e imediatas. Recomenda-se ampliar as formas de diagnosticar e tratar assertivamente a depressão em idosos.

Palavras-chave Suicídio em idosos, Depressão, Autópsia psicológica 


\section{Introdução}

No artigo se analisa as diferentes faces da depressão encontradas em autópsias psicológicas de pessoas entre 60 e 80 anos que morreram por suicídio. Aprofunda a dimensão psicopatológica de uma pesquisa feita com apoio da Fundação de Amparo à Pesquisa do Rio de Janeiro (Faperj) e que envolveu revisão de literatura sobre o tema ${ }^{1}$, visão epidemiológica do suicídio em idosos no país e no estado do Rio de Janeiro ${ }^{2}$ e uma análise de autópsias psicológicas no município do Rio ${ }^{3}$. O estudo, embora local, dialoga com as literaturas nacional e internacional. A maior parte das histórias é da classe média, do gênero feminino e apresenta formas de perpetração típicas de área urbana $^{2}$. No entanto, os vários graus psicopatológicos descritos sugerem uma reflexão para além do gênero ou da área geográfica, pois aponta padrões de adoecimento e comorbidades da pessoa idosa que devem ser conhecidos e cuidados pela área social e da saúde.

As taxas de suicídio variam entre países, por idade, sexo, raça e etnia, sendo altas na Europa Oriental, medianas nos Estados Unidos, Europa Ocidental e Ásia e baixas nas Américas Central e do Sul. Na maioria dos países os homens têm taxas mais elevadas de suicídio do que as mulheres, numa variação de 3:1 a 7,5:14. Em diversos países o maior grupo de risco para suicídio é o de pessoas acima dos 65 anos, aumentando com a idade $^{4-8}$. Estudos apontam que a maior parte dos idosos que morreram por suicídio tinha algum transtorno mental, sendo que de $71 \%$ a $90 \%$ deles sofriam algum grau de depressão $0^{5,9-13}$.

A prevalência de sintomas depressivos em idosos nos Estados Unidos ${ }^{10}$ oscilou entre 10\% e 15\% em 2006 e no Brasil entre 6\% e 12\% no ano de 2003 , sendo a quinta dentre as principais doenças entre pessoas com 60 anos ou mais em nosso país ${ }^{14}$. A depressão maior, no entanto, é relativamente rara nesse grupo etário, estando presente em 1 a $2 \%$ das pessoas acima de 65 anos $^{11}$. A prevalência da depressão maior varia entre $6 \%$ a $9 \%$ nos serviços americanos de atenção primária para idosos enquanto os sintomas depressivos moderados afetam de $17 \%$ a $37 \%$. De modo semelhante, estudos reportaram 7\% de ideação suicida em idosos e $30 \%$ em pacientes com depressão profunda, nesse mesmo tipo de serviço ${ }^{15}$. A depressão tem forte tendência de reaparecer em idosos em 50\% a 90\% dos casos num período de dois a três anos ${ }^{16}$. Por isso a meta do tratamento é não apenas a recuperação, mas prevenir sua recorrência e buscar reduzir o risco de autoaniquilamento?.
Para Conwell e Thompson 5 , o número de doenças aumenta o risco cumulativo de suicídio. Idosos têm seis vezes mais chance de adquirir alguma doença física do que jovens ${ }^{17} \mathrm{e}$ estão sujeitos a comorbidades múltiplas, associadas a variadas dosagens medicamentosas e declínio funcional, o que aumenta o risco de suicídio ${ }^{5}$. Além disso, há complicadores no tratamento medicamentoso da depressão como a vulnerabilidade a efeitos adversos, comorbidade médica competindo com deficiências funcionais, cognitivas e estigma social. Esses fatores dificultam a prescrição, o início e a adesão ao tratamento ${ }^{15}$. Os idosos são mais relutantes para se queixar de depressão ou explicitar ideias suicidas, por isso, poucos são diagnosticados e só uma minoria é tratada ${ }^{18}$.

Da ideia inicial de "queda de pressão" à noção geológica de "deformidade de terreno", o conceito depressão passa a ser associado a um estado de espírito ou sentimento, caracterizado pela ideia de diminuição da vivacidade e de baixa afetiva por quem a vivencia. Do ponto de vista médico, a depressão é um quadro clínico heterogêneo, cujo padecimento se apresenta em graus e é diferenciado por causas orgânicas, ambientais ou circunstanciais, respectivamente, endógenas, relativas a uma predisposição hereditária; exógenas, relacionadas a fatores psicossociais e psicogênicas, como reação psicológica desencadeada em resposta a um evento precipitante ${ }^{19}$.

Na clínica psiquiátrica se faz a distinção entre a depressão que aparece como sintoma e a depressão como síndrome. Enquanto sintoma, o afeto depressivo pode aparecer como um dos elementos sintomáticos de uma doença física, como o câncer ou o HIV-AIDS ${ }^{19}$; ou como reação a um trauma psicológico, como no Transtorno do Estresse PósTraumático (TEPT) que é resultado de intenso sofrimento psicossocial difícil de ser absorvido pelo organismo ${ }^{20}$; ou pode ser efeito do uso continuado de certas drogas que alteram o humor (como o haloperidol); ou ainda ser sinal de reação orgânica a doenças do sistema nervoso central (tumor cerebral, arterosclerose). Na forma de sintoma, a depressão é uma ocorrência depressiva secundária, diferente do grupo das depressões primárias, que representa uma entidade patológica autônoma, independente de causas externas. Essa distinção é feita para separar quadros sintomáticos e psiquiátricos, mostrando que a depressão como síndrome é uma entidade mórbida, ou seja, o afeto deprimido que o paciente experimenta é atribuído à depressão que ele apresenta ${ }^{19}$.

Inúmeras classificações têm sido feitas até as revisões atuais da Classificação Internacional de 
Doenças e Causas de Morte (CID 10)21 e do Diagnostic and Statistical Manual of Mental Disorder (DSM-III-R e IV) $)^{22}$, quando os transtornos depressivos aparecem como depressão maior e distimia depressiva junto aos transtornos bipolares (misto, maníaco, depressivo e ciclotímico). A depressão é um transtorno do humor que oscila entre moderado e profundo, de curta ou longa duração ${ }^{9}$ que apresenta humor alterado, perda de interesse e de prazer pela vida e reduzido níveis de energia ${ }^{12,22}$. Enquanto que entre jovens e adultos de meia idade a depressão aparece associada a aspectos emocionais e cognitivos, como tristeza e negatividade, entre idosos surge associada a sintomas somáticos como cansaço e fadiga, distúrbios do sono e do apetite, sentimentos de desesperança e pensamentos sobre a morte ${ }^{12}$.

A depressão costuma estar associada a algum tipo de perda na habilidade física, aparência, papel social, morte de outros, segurança financeira. Adultos depressivos sentem como se seu mundo tivesse se estreitado, suas escolhas ficassem menores, seus interesses e preferências menos disponíveis. Eles sentem uma tristeza insuportável. A ideação suicida está associada à necessidade que o idoso sente de resolver ou por fim a uma situação intolerável, a sentimentos de desesperança, às incapacidades sentidas de fazer as coisas de forma melhor. A depressão é frequentemente acompanhada por somatizações e reclamações físicas. Os sintomas da depressão são: ansiedade exagerada; dependência acompanhada de culpa; rigidez alternada por impulsividade?.

Este artigo se debruça especialmente na pergunta sobre o papel da depressão como fator de risco para o suicídio e se a existência de comorbidades aumenta esse risco. Um estudo feito com pacientes com depressão maior, com e sem história de tentativa de suicídio, com e sem experiência de ideação suicida, com idade entre 50 e 87 anos ${ }^{23}$ concluiu que participantes com história de tentativa de suicídio eram mais jovens e mais deprimidos; a presença da comorbidade psiquiátrica diferenciava os que portavam graus mais severos de ideação suicida; a depressão estava relacionada com a severidade da ideação suicida; e a alta impulsividade distinguia os que tinham história de tentativas de suicídio. Destaca-se que é fundamental diagnosticar e tratar a depressão em idosos, especialmente quando surge em diferentes graus e com ideação suicida ${ }^{9,15,24}$.

\section{Material e Método}

Esta pesquisa utilizou o método da autópsia psicológica de Schneidman ${ }^{25}$ e levou em conta nossa experiência em estudos anteriores ${ }^{26,27}$. A autópsia psicológica é um método retrospectivo que reconstitui as condições de saúde física e mental e as circunstanciais sociais das pessoas que se suicidaram a partir de entrevistas com familiares e informantes próximos às vítimas, em geral, com pequenas amostras e sem pretensão de generalização ${ }^{25,28}$. Ela permite contextualizar dados na história psicossocial e limita-se ao conteúdo colhido por informantes próximos ou fontes oficiais (laudos periciais, prontuários médicos, etc.). Recomenda-se uma análise que contraste os achados qualitativos com evidências de importantes estudos quantitativos e clínicos.

Apresenta-se uma terminologia consensual extraída de recentes publicações ${ }^{4,29-31}$. O suicídio é visto como um ato intencional para acabar com a própria vida. Pensamentos e comportamentos suicidas não fatais são agrupados em três categorias: ideação suicida, pensamentos que fomentam a intenção de acabar com a própria vida; plano suicida, formulação de um método para acabar com a própria vida; tentativa de suicídio, comportamento voltado para se ferir em que há alguma intenção de se matar. Ela pode resultar em nenhum ferimento, em ferimento ou em morte. Se a tentativa de suicídio resulta em morte, então é definida como suicídio. A literatura tem utilizado também o termo comportamento suicida, como um tipo de conduta da pessoa que busca se ferir (de modo explícito ou implícito), seja agindo contra si e ameaçando sua vida, seja deixando pistas verbais ou comportamentais.

A amostra é composta por oito informantes, todos na faixa entre 31 e 60 anos, ligados a idosos entre 60 e 80 anos, duas filhas, um filho, um neto, uma irmã, um amigo e duas vizinhas, sendo seis adultos de meia idade, um jovem e um idoso, todos na faixa entre 31 e 60 anos. Foram feitas oito entrevistas reconstituindo as causas do suicídio em idosos entre os anos de 2004 e 2007.

Elaborou-se um roteiro de entrevista adaptado e descrito em estudos anteriores s, $^{3,27}$ reunindo três tipos de informação: (a) ficha de identificação pessoal e social da pessoa que morreu por suicídio e dados gerais do informante; (b) genograma da família da vítima para reconstituir alianças, conflitos, rede de relações, acontecimentos críticos de impacto pessoal, social, econômico ou cultural em três gerações e o padrão de morbidade ou mortalidade associado ao suicí- 
dio; (c) entrevista semiestruturada para detalhar o estado mental que antecedeu o suicídio, descrever circunstâncias associadas ao comportamento suicida e possíveis causas, reconstituir o suicídio e a gravidade de fatores que o envolveu, compreender seu impacto na família e os problemas que esta enfrenta atualmente.

Os dados foram coletados de três fontes: laudos periciais; contato telefônico com informantes em potencial; entrevista com familiares ou pessoas próximas por até duas horas de duração, todas gravadas e transcritas, após assinatura de Termo de Consentimento Esclarecido por parte dos participantes.

Partiu-se de 60 laudos periciais, acessados no Instituto de Criminalística Carlos Ebóli no Rio de Janeiro (ICCE-RJ). Dessa amostra, foram selecionados 24 laudos de idosos que cometeram suicídio, com idade entre 60 anos ou mais. Enviou-se 48 cartas para familiares e síndicos dos endereços encontrados nos laudos, informando sobre a pesquisa e convidando-os a colaborar com o estudo. Também foram feitos contatos telefônicos com a quase totalidade das pessoas incluídas na amostra, sendo que quase metade da mesma não foi alcançada.

Houve o retorno de apenas quatro cartas, com adesões ao estudo. Todos os oito aceites, no entanto, foram conseguidos através de contatos telefônicos com informantes em potencial, o que personalizou o contato, assegurou os cuidados éticos e o sigilo de informações, bem como esclareceu os procedimentos e os cuidados adotados na entrevista. Houve três recusas por telefone.

Como se partiu de laudos de morte, uma fonte impessoal, o maior desafio deste estudo foi localizar informantes em potencial e conseguir construir confiança. Houve um fator facilitador, o fato de que as pessoas que constam dos laudos, em geral, são as mais próximas das vítimas e, por isso, puderam ser mais facilmente localizadas. As entrevistadoras são psicólogas com experiência clínica e no trato com famílias, que conhecem o tema e a metodologia, o que propiciou uma revisão compreensiva e um manejo clínico dos conteúdos, com orientações voltadas para a saúde dos familiares.

\section{Resultados}

Os casos estão agrupados por semelhanças e diferenças quanto à ocorrência de depressão, à presença de comorbidades mentais ou físicas, à presença de fatores psicossociais ou socioeconômi- cos, com ou sem sintomas depressivos. Foram dois casos de suicídio masculinos, na faixa de 60 anos e seis de feminino na faixa de sessenta, setenta e oitenta anos. Houve cinco quedas de altura, todas perpetradas por mulheres; dois enforcamentos, masculino e feminino; e um envenenamento perpetrado por homem. Ressalta-se o ineditismo de se acessar mais casos do sexo feminino (de 2,4/100.000 a 2,6/100.000) em contraste com a maior prevalência masculina (de 8,7 / 100.000 a 15,7/100.000) entre 1980 e $2006^{2}$, das classes média e média alta, a quase totalidade composta por brancos. Acredita-se que a predominância de casos da zona sul, área de maciça presença de idosos no município do Rio, esclareça esse recorte.

Abrangeram-se dois níveis de análise: (1) Depressão e causas do suicídio: presença ou ausência de depressão, gravidade e duração, natureza do afeto depressivo como reação sintomática ou sindrômica, existência de comorbidades. Verificou-se presença ou ausência de ideação suicida e de tentativa de suicídio. A ocorrência de comportamentos suicidas, mediada por sinais verbais, comportamentais, situacionais ou sindrômicos foi reconstituída, observando-se traços de personalidade; (2) Efeito de estressores psicossociais ou socioeconômicos: fatores de risco e protetores, o padrão de funcionalidade global do idoso em estudo e as causas do suicídio.

\section{Depressão e causas do suicídio}

\section{A depressão como ocorrência primária e secundária}

Entre os seis suicídios femininos estudados, encontram-se três quadros depressivos distintos. O primeiro, associado a perdas (morte de entes queridos e separação conjugal) e a acidentes (acidente de trânsito que ameaçou gravemente a vida de uma filha). Esse quadro depressivo, que apareceu como reação sintomática, eclodiu a primeira vez após grave acidente de carro sofrido pela filha, num quadro de comorbidade do transtorno de estresse pós-traumático (TEPT). O quadro depressivo reapareceu mais duas vezes, sempre associado a algum fator estressor que funcionava como gatilho, desencadeando a depressão. Na segunda vez, o estressor foi a ocorrência de violência no local de trabalho, por meio de uma ameaça física de um aluno a essa mulher que era professora. E na terceira vez, o estressor foi a aposentadoria abrupta, vivenciada como perda de recursos. Em todas as vezes que a depressão apareceu, foi tratada como diagnóstico 
primário e não como comorbidade do TEPT. Por isso, o tratamento não levou em conta que a cada reaparecimento da depressão, o sistema de defesa do organismo encontrava-se mais fragilizado e menos capaz de fazer o coping e superar a situação dolorosa. Neste caso, o TEPT não foi tratado, apenas a depressão, através de acompanhamento psiquiátrico com uso de antidepressivos.

$\mathrm{O}$ segundo caso foi um suicídio associado à depressão aguda, meses após o falecimento do marido, de um companheiro de cinquenta anos de intensa vida conjugal e familiar. A morte do marido veio após seis meses de internação hospitalar. Os sintomas depressivos aqui são pouco claros.

O terceiro caso esteve associado a uma depressão profunda e crônica, após dez anos de tratamentos sucessivos e pouco exitosos, uma vez que essa pessoa idosa tinha reações paradoxais aos medicamentos. Ela havia tido uma vida familiar, social e profissional intensa. Era uma intelectual com livros publicados, cuja depressão eclodiu a primeira vez após a perda de um irmão caçula, muito ligado a ela. Desde então foi difícil envelhecer, viver outras perdas e ver sua capacidade intelectual, criatividade e concentração se deteriorar. Apesar de esta idosa ter tido acesso a todo o tipo de tratamento disponível, de ser acompanhada pelas filhas sistematicamente, sua depressão não apresentava melhora. Por fim, o médico que a acompanhara nos últimos anos comunicou à família que nada mais podia fazer, por causa da falta de adesão ao tratamento que se evidenciou na fase final. As filhas buscaram outro profissional e a família foi avisada por ele que a medicação trazia risco de suicídio e que ela necessitaria de vigilância permanente. Essa responsabilidade foi deixada com a família e a inaptidão de prosseguir com o tratamento foi atribuída à cliente, ficando as reações paradoxais ao tratamento e o excessivo uso de medicamentos não problematizados. Justamente na troca medicamentosa, mesmo sob vigilância de dia e de noite de um cuidador, a idosa suicidou-se.

Em nenhum desses três casos, os filhos observaram comportamento suicida, embora duas dessas mulheres apresentassem forte ideação. Não nos foram relatadas tentativas de suicídio. Houve percepção de sinais verbais quanto ao profundo sofrimento e desejo de morrer, bem como, houve observação da reação comportamental de quietude e isolamento, no caso em que nenhum sinal de depressão foi identificado.

Uma vivência de desamparo econômico foi o estressor associado à depressão e ao suicídio no caso de uma mulher aposentada; o desamparo afetivo pela perda do cônjuge no caso de suicídio de uma viúva; e depressão profunda e de difícil remissão, associada à desesperança e à perda de habilidades funcionais - como efeito de intoxicação medicamentosa por uso prolongado e recorrente de antidepressivos - foi o desencadeador do suicídio de uma mulher escritora e reconhecida socialmente. Temos respectivamente uma depressão psicogênica (provocada por gatilhos traumáticos), uma depressão exogênica (como reação a uma morte inaceitável) e uma depressão endogênica (atribuída a uma tendência orgânica).

\section{Depressão e comorbidade física e mental}

Entre os seis casos de suicídio feminino, dois estiveram associados a transtorno mental, com características distintas. O quarto caso foi de uma médica com transtorno bipolar que, com prolongados cuidados psiquiátricos e psicoterápicos, conseguiu manter-se compensada por muitos anos e seguir sua carreira profissional no serviço público de forma íntegra. O transtorno bipolar afetou outros membros da família e há o relato de que sua mãe faleceu de consequências advindas de uma tentativa de suicídio associada a surto psicótico. Inúmeros fatores de risco fragilizaram a condição dessa idosa além do transtorno bipolar: tendo sido uma mulher de beleza exuberante viu-se com dificuldade para envelhecer, especialmente após adquirir câncer nos seios, tê-los amputado e descobrir que sua doença evoluía para uma fase terminal. Essa situação gerou-lhe uma desorganização psíquica, acelerou uma tentativa de suicídio por ingestão de medicamentos e uma internação psiquiátrica e depois, o suicídio. Este foi um evento causado por depressão associada a transtorno de humor e comorbidade com doença física grave. A presença e o acompanhamento familiar e de amigos não foi suficiente para detê-la.

O quinto caso era de uma pessoa que sofria de transtorno mental, fumava compulsivamente e era viciada no jogo do bingo, uma comorbidade entre sintomas psiquiátricos e traços compulsivos. Essa mulher de temperamento difícil tolhia a presença dos que se propunham a ajudá-la. Havia dois anos que vivia acabrunhada por um estressor psicossocial a partir da morte da mãe e da tia que cuidavam dela. Sua ligação com ambas era fortíssima. O fumo compulsivo e os traços psicóticos deixaram essa mulher com características semelhantes a pacientes internados em hospícios, que vagam solitários pelos corredores dos hospitais. Aqui, no entanto, ela transitava no espaço urbano, des- 
cuidada como uma mendiga, à sombra dos laços afetivos e sociais que se foram, mas continuavam a povoar-lhe a memória e as emoções. As circunstâncias parecem falar de uma depressão psicótica acompanhada de alucinações sinestésicas e vivência delirante. O estado geral de desleixo com o corpo e com a higiene era visível nos dias que antecederam ao autoaniquilamento.

Enquanto no primeiro caso, o fator agravante foi uma doença terminal desorganizando um transtorno mental que se manteve compensado por tantos anos, no segundo, o transtorno mental foi determinante na fragilização dessa pessoa que morreu sozinha e sem elos e referências familiares. O descuido de sua aparência física e do ambiente em que vivia, revela que $o$ rico pode ficar tão desassistido quanto o pobre, embora sob o teto de um apartamento de luxo regado por recheada conta bancária. Neste caso, os parentes só apareceram para disputar a herança, conforme relata uma vizinha.

\section{Fatores psicossociais e socioeconômicos}

O sexto caso não envolveu nem depressão e nem transtorno mental. A mulher que optou pelo autoextermínio era tão dedicada às filhas e aos netos que acabou perdendo a noção das fronteiras de como e de quanto deveria supri-los. Apesar de as filhas estarem casadas e com filhos, a marca dessa rede familiar era a dependência da avó, seja em relação à moradia, seja em relação às ajudas financeiras que ela distribuía. Netos e bisnetos com deficiências ou doenças crônicas e renda reduzida eram os estressores psicossociais que funcionavam como justificativa para usufruto do dinheiro, do tempo e da energia dessa idosa. Quando prometeu que iria morrer sem dar trabalho, essa idosa parecia acreditar que não tinha direito aos cuidados dos familiares. Ela tirou sua vida, sem deixar pelo menos um bilhete. Segundo o neto, ela fez com sua morte, o que deveria ter feito sempre: dar limite aos familiares, diferenciando sua própria existência da vida dos que dela não queriam se desprender.

No sétimo e oitavo caso, os suicídios masculinos foram causados por estressores socioeconômicos, declínio na vida pessoal, profissional e social, quando uma queda gradual no padrão socioeconômico abalou a identidade masculina. Um deles viveu esse declínio passando por vários fatores de risco: crise econômica no país (Plano Collor); cassação do diploma de advogado; queda no status social e econômico; rompimento com o núcleo familiar; alcoolismo; solidão e tra- ços depressivos. O segundo era imigrante e viveu o sonho de montar o próprio negócio em terra estrangeira. Conseguiu, mas, depois, viu seu negócio ruir. Com grande tristeza e decepção, submeteu-se a subempregos como porteiro de edifícios, situação que lhe roubou o ânimo e minou o seu senso de merecimento e o sentido da vida, deixando-o com traços depressivos.

$\mathrm{Na}$ descrição dos dois suicídios masculinos, houve relato de intensa ideação suicida e ameaça de morte autoinfligida, embora a reação de parentes e amigos tenha sido de descrença em relação a tais ameaças, seja por interpretá-las como chantagem emocional, seja por não acreditar que esses idosos seriam capazes de dar cabo à vida. Uma reação depressiva exógena apareceu nesses dois casos, associada a fatores socioeconômicos e crises existenciais: no advogado como comorbidade associada ao alcoolismo e a uma vivência de decadência, fracasso e solidão, incrementada pela fragilização dos laços familiares. No caso do imigrante europeu, à perda do sentido da vida e à sensação de fracasso como provedor. Por isso, a presença e a proximidade do núcleo familiar não funcionaram como fator protetor.

Os dois casos masculinos e o da senhora superprotetora em relação à família revelam a força de estressores psicossociais e socioeconômicos na vida de idosos, com e sem a presença da depressão, mas associados a conflitos familiares ou a crises existenciais. Não houve tentativa de suicídio prévia em nenhum desses três casos e a ideação suicida ficou implícita na fala da idosa e explícita na fala dos dois homens. Por outro lado, quando os estressores principais são socioeconômicos, a depressão ainda assim acontece, mas é secundária e reativa, ficando como pano de fundo de uma crise existencial num cenário social específico.

\section{Discussão}

Serão discutidas e analisadas as principais circunstâncias relacionadas ao ato suicida dos casos que foram apresentados. Apontam-se o grau de letalidade do plano suicida executado; as condições físicas e mentais das vítimas antes do suicídio, visão sobre a vida e o sentido atribuído à própria morte pelas vítimas; o tipo de apoio de familiares e amigos ou grau de isolamento e solidão encontrados; a presença ou ausência de acompanhamento profissional na área da saúde.

Três idosas se atiraram pela janela do apartamento em que moravam, do sexto, sétimo e 
oitavo andar respectivamente, mas nenhuma delas havia tentando antes. Na depressão vivida pela que teve como fato desencadeante a aposentadoria, encontramos fadiga, dificuldade crônica para dormir e ansiedade. A depressão reapareceu de modo abrupto e intenso, quando a saída do trabalho foi interpretada como ameaça à estabilidade social e econômica, embora esta ameaça fosse apenas uma fantasia. Nesse cenário, a depressão veio associada à intensa ideação suici$\mathrm{da}$, indicando sério risco de autoaniquilamento, apesar do apoio familiar e da continência afetiva existente, da história de superação na vida pessoal e profissional e da história de remissão de quadros depressivos anteriores. Na depressão vivida pela viúva que tinha uma relação inseparável com o marido, nenhum sinal de risco de suicídio foi observado, exceto certo distanciamento do convívio, comportamento que muitos estudiosos recomendam acompanhar como preditivo ${ }^{32,33}$. Essa idosa tinha hipotireoidismo e hipocondria, acompanhada da preocupação em não ficar gorda e em cuidar da aparência. O suicídio ocorreu poucos meses depois da morte do marido.

Já a depressão profunda e prolongada da escritora esteve associada à intensa ideação suicida, acompanhada de descrença nos tratamentos não exitosos e de um sofrimento abissal. Ela dizia: Eu estou num buraco, como se eu tivesse num poço, que eu não consigo ver a luz. Eu não tenho mais gosto pelas coisas. Eu acho que eu não tenho mais jeito! Essa depressão não me larga, é uma coisa química, está no corpo. A sensação de impregnação medicamentosa é aqui evidenciada, o que nos faz pensar nos limites dos recursos farmacológicos e dos efeitos nocivos que podem produzir no longo prazo. Essa idosa foi flagrada exibindo comportamento suicida, quando provavelmente estivesse planejando o ato fatal, subindo num banco próximo a uma janela. Apesar do apoio psiquiátrico e do apoio familiar, o suicídio veio pôr fim ao sofrimento e à depressão. Neste último caso, o risco de suicídio foi verbalizado por profissionais de saúde, nos outros dois, o ato surpreendeu a todos.

No suicídio de duas idosas, a depressão psicótica veio associada à doença física e mental: câncer em fase terminal, numa portadora de transtorno bipolar e vivência delirante de câncer de pele, na outra, com transtorno mental. Ambas se atiraram do décimo primeiro andar, a primeira foi encontrada com os dedos em forma de figa, como num último gesto de esperança. $\mathrm{E}$ a segunda deixou um bilhete para a síndica do prédio, no qual dizia: Eu não vou precisar mais de ninguém para ficar comigo. Esta frase veio em resposta à recomendação da vizinha de que ela precisava buscar ajuda, exatamente no dia que antecedeu o suicídio. A primeira idosa havia acabado de voltar de uma internação psiquiátrica e se jogou pela janela do apartamento em que morava, na hora em que a acompanhante cochilava. A segunda foi encontrada sem banho, com umas duzentas guimbas de cigarro no cinzeiro, o que parece indicar alto grau de ansiedade, isolamento e solidão. Ambos são casos de idosos com altíssimo risco de suicídio, pela associação cumulativa de transtornos metais, físico e traços compulsivos, com e sem apoio familiar, com e sem tratamento psiquiátrico.

Por fim, analisamos o suicídio por enforcamento de um homem e de uma mulher e por envenenamento de outro homem. A mulher, após conflito familiar e promessa de que não daria trabalho aos familiares e tendo afirmado que eles a encontrariam morta, enforcou-se na sala do apartamento em que morava. A ideia subentendida de que ela estaria "poupando" os familiares com sua morte, e a ausência de qualquer transtorno físico ou mental numa pessoa de personalidade ativa, cheia de ânimo e vitalidade, coloca o suicídio como uma escolha. Aqui, a escolha existencial parece um sintoma social do mundo contemporâneo que não reserva espaço familiar adequado para a pessoa idosa. O homem que também se enforcou atribuiu a si mesmo a sentença de morte, quando dizia aos familiares: $u m$ homem que não é mais homem, não precisa mais viver. Sua morte foi ritualizada: após um banho e depois de ter vestido a melhor roupa, enforcou-se na entrada de serviço do prédio em que morava e trabalhava como porteiro, no turno da noite, impactando duplamente a família e o local de trabalho. Embora ele ameaçasse: qualquer dia eu vou me matar, não consigo mais ficar aqui, sua ideação suicida não foi vista como fator de risco pelo médico que o examinou, conforme relatou a filha. Os dois idosos que se enforcaram fizeram igualmente uma escolha existencial planejada. Nem o suporte familiar, nem o apoio da área da saúde funcionaram como fatores protetores nesses casos.

O homem que optou pelo envenenamento deixou um bilhete dizendo: O infarto é iminente e a solidão corrói. Nesta frase derradeira, mostra que visualizava um desfecho ruim e solitário para sua existência, o qual foi por ele controlado quando antecipou a própria morte, ao comprar dois vidros de veneno e ingerir o conteúdo de um, não deixando dúvidas sobre sua intenção de 
morrer. No armário, ele fixou os contatos de um dos filhos e do melhor amigo. Essas pessoas cuidaram da liberação do corpo, do sepultamento e de detalhes após o óbito. Esse homem deixou seus pertences organizados, inclusive tarefas profissionais já prontas para serem encaminhadas, revelando que a morte autoinfligida foi premeditada. A comorbidade entre traços depressivos e alcoolismo está associada a uma visão da própria vida, cujo desfecho se relacionou a um progressivo declínio pessoal e social, poupando a si mesmo de ainda maiores sofrimentos.

\section{Considerações finais}

Como o acesso a casos se deve a uma amostra por conveniência, ou seja, aqueles disponíveis no momento da pesquisa, este estudo acabou reunindo dados de uma minoria inesperada, mulheres, com menor prevalência de suicídio e menos estudadas. $\mathrm{O}$ artigo analisou casos de classe média e alta e de pessoas brancas, chamando atenção para o sofrimento presente em situações de amparo ou de declínio social e recomenda que se façam estudos de todos os estratos sociais, por diferenças de gênero, raça e etnia.

Os casos de suicídio de idosos aqui analisados ocorreram, na maior parte das vezes associando depressão, adoecimentos físicos, mentais ou limites funcionais, fatores situacionais e sociais, perdas, saída do mundo do trabalho e queda no padrão de vida, revelando sua causalidade múltipla. Quanto maior for a soma de doenças associadas à depressão e quanto mais grave for o limite funcional real ou imaginado, maior o risco de autoaniquilamento. Quanto mais incisivas as pressões sociais ao longo de um ciclo de vida, mais grave o risco de suicídio, pois as defesas dos idosos tendem a estar mais fragilizadas. Além disso, há risco de suicídio associado à mudança na prescrição medicamentosa e à troca de médico em fases críticas do tratamento.

Há convergências entre os resultados aqui encontrados e dados apontados pela literatura. Predominam as associações entre suicídio e depressão na quase totalidade dos casos, sendo que uma minoria não mostra essa vinculação. Um único caso em que sintomas de depressão não se revelaram, evidencia que o suicídio de um idoso pode estar atrelado a fatores relacionais e sociais. Este caso nos leva a interrogar sobre o lugar do idoso na vida da família moderna e a questionar porque razão alguns idosos têm sido mantidos no lugar de provedor, além de suas possibilidades psicossociais.

Mas a depressão que encontramos associada ao risco de suicídio tem múltiplas faces: apareceu como diagnóstico primário ou secundário, como sintoma associado a outras morbidades ou como reação a estressores sociais, cada qual demandando diferentes condutas e procedimentos terapêuticos. Nos cuidados com esses idosos em potencial risco, um fator crucial é, portanto, compreender a interação entre variáveis, sintomas psiquiátricos ou clínicos, fatores de risco e protetores, traços de personalidade, eventos circunstanciais, continência familiar e capacidade de suporte da área da saúde. Cada padrão interativo revela que o suicídio é multicausal e singular, pois cada pessoa reage e interpreta o sofrimento que a atinge de um modo particular.

Encontrou-se também associações entre variáveis como aponta a literatura. A maior parte dos suicídios entre idosos, além da depressão como um forte fator desencadeante, também é frequentemente precedida de intensa ideação suicida. Nos casos analisados - e são poucos para permitir generalizações - em apenas um houve tentativa de suicídio e só dois idosos deixaram bilhetes. No entanto, na maioria das situações, pareceu-nos que os idosos planejaram cuidadosamente sua morte e a rapidez com que os planos foram executados chama atenção. Os dados mostram que, embora a maioria dos idosos tenha deixado pistas verbais, comportamentais ou situacionais, os pedidos de ajuda exigiriam muita sensibilidade dos familiares e cuidadores. Pois, na maioria das vezes, pistas verbais ou comportamentais são exibidas, mas, parentes e amigos tendem a não levá-las a sério.

Em resumo, a associação entre depressão e comorbidade múltipla agrava o prognóstico do caso e amplia cumulativamente o risco de suicídio. A depressão e as ideações suicidas são grandes fatores de risco que justificam medidas preventivas e imediatas, tendo em vista que o idoso muito rapidamente coloca em prática seu plano suicida. Tudo isso desafia a saúde pública quanto à prevenção, sobretudo dos casos de mais gravidade, o que demanda formas de suporte mais complexas, capazes de dar conta das diferentes faces que o problema apresenta. 


\section{Colaboradores}

$\mathrm{O}$ artigo foi elaborado e revisado em conjunto por FG Cavalcante e MCS Minayo. O projeto foi coordenado e analisado por MCS Minayo, os dados coletados, organizados e analisados por FG Cavalcante e RM Mangas. Não há conflito de interesses.

\section{Referências}

1. Minayo MCS, Cavalcante FG. Suicídio entre pessoas idosas: revisão de literatura. Revista de Saúde Pública 2010; 44(4):750-757.

2. Minayo MCS, Pinto LW, Assis SG, Cavalcante FG, Mangas RMN. Trends in suicide mortality among Brazilian adults and elderly, 1980-2006. Rev Saude Publica 2012; 46(2):300-309.

3. Minayo MCS, Cavalcante FG, Mangas RM, Souza JRA. Autópsias psicológicas sobre suicídio de idosos no Rio de Janeiro. Cien Saude Colet 2012; 17(10):2773-2781.

4. Nock MK, Borges G, Bromet EJ, Cha CB, Kessler $\mathrm{RC}$, Lee S. Suicide and Suicidal Behavior. Epidemiol Rev 2008; 30(1):133-154.

5. Conwell Y, Thompson C. Suicidal Behavior in Elders. Psychiatr Clin North Am 2008; 31(2):333-356.

6. World Health Organization (WHO). Mental Health Suicide Preventtion (SUPRE). [serial on line]. [accessed 2007 Oct 16]. Disponível em: http:// www.who.int/ mental_health/prevention/suicide/ suicideprevent/ en/ WorldHealth Organization

7. Beautrais AL. Suicides and serious suicide attempts: two populations or one? Psychol Med 2001; 31(5): 837-845.

8. Conwell Y, Lyness JM, Duberstein P, Cox C, Seidlitz L, DiGiorgio A, Caine ED. Completed suicide among older patients in primary care practices: a controlled study. J Am Geriatr Soc 2000; 48(1):23-29.

9. Mitty E, Flores S. Suicide in Late Life. Geriatr Nurs 2008; 29(3):160-165.

10. Beeston MD. Older People and Suicide. Staffordshire: Centre for Ageing and Mental Health, Staffordshire University; 2006.

11. Fiske A, Jones RS. Depression. In: Johson ML, editor. The Cambridge Handbook of Age and Ageing. Cambridge: Cambridge University Press; 2005. Cap 3. p. 245-251.

12. Power DV, Thompson L, Futterman A, GallagherThompsom D. Depression in Later Life: epidemiology, assessment, impact and treatment. In Gotlib, IH, Hammen CL, editors. Handbook of Depression. New York: Guilford Press; 2002.

13. Shah A, Bhat R. Are elderly suicide rates improved by increased provision of mental health service resources? A cross-national study. Int Psychogeriatr 2008; 20(6):1230-1237.

14. Camarano AA, Kanso S, Pasinato MT, Leitão e Melo J. Idosos brasileiros: indicadores de condições de vida e de acompanhamento de políticas. Brasília: Presidência da República, Subsecretaria de Direitos Humanos; 2005.

15. Bruce ML, Have TRT, Reynolds CFIII, Katz II, Schulberg HC, Mulsant BH, Brown GK, McAvay GJ, Pearson JL, Alexopoulos GS. Reducing Suicidal Ideation and Depressed Symptoms in Depressed Older Primary Care Patients. A Randomized Controlled Trial. JAMA 2004; 291(9):1081-1091.

16. Reynolds CFIII, Dew MA, Pollock BG, Mulsant BH, Frank E, Miller MD, Houck PR, Mazumdar S, Butters MA, Stack JA, Schlernitzauer MA, Whyte EM, Gildengers A, Karp J, Lenze E, Szanto K, Bensasi S, Kupfer DJ. Maintenance Treatment of Major Depression in Old Age. N Engl J Med 2006; 354(11):11301138. 
17. Tadros G, Salib E. Elderly suicide in primary care. Int J Geriatr Psychiatry 2007; 22(8):750-756.

18. McIntosh JL, Santos JF, Hubbard RW, Overholser JC. Elder suicide: research, theory, and treatment. Washington: American Psychological Association; 1994.

19. Coser O. Depressão: clínica, crítica e ética. Rio de Janeiro: Editora Fiocruz; 2003.

20. Cavalcante FG, Morita PA, Haddad SR. Sequelas invisíveis dos acidentes de trânsito: o transtorno do estresse pós-traumático como problema de saúde pública. Cien Saude Colet 2009; 14(5):795-804.

21. Organização Mundial de Saúde (OMS). Classificação Internacional de Doenças e Causas de Morte (CID 10). 10a revisão. Washington: OMS; 2006.

22. American Psychiatric Association. Diagnostic and Statistical Manual of Mental Disorder; DSM-III-TR; 1987. (Original publicado em 1980) e DSM-IV-TR (2000). (Original publicado em 1994). Arlington: APA; 1987.

23. Useda JD, Duberstein PR, Conner KR, Conwel Y. Personality and Attempted Suicide in Depressed Adults 50 Years of Age and Older: A Facet Level Analysis. Compr Psychiatry 2004; 45(5):353-361.

24. Unützer J, Tang L, Oishi S, Katon W, Williams JW Junior, Hunkeler E, Hendrie H, Lin EH, Levine S, Grypma L, Steffens DC, Fields J, Langston C; IMPACT Investigators. Reducing suicidal ideation in depressed older primary care patients. J Am Geriatr Soc 2006; 54(10):1550-1556.

25. Schneidman ES. The psychological autopsy. Suicide Life-Threat Behav 1981; 11(4):325-340.

26. Cavalcante FG, Minayo MC. Organizadores psíquicos e suicídio: retratos de uma autópsia psicossocial. In: Almeida-Prado MCC, organizador. O mosaico da violência. São Paulo: Vetor; 2004. p. 371-431.

27. Minayo MCS, Cavalcante FG, Souza ER. Methodological proposal for studying suicide as a complex phenomenon. Cad Saude Publica 2006; 22(8):15871596.
28. Hawton K, Appleby L, Platt S, Foster T, Cooper J, Malmberg A, Simkin S. The psychological autopsy approach to studying suicide: a review of methodological issues. J Affect Disord 1998; 50(2-3):269-276.

29. O`Carroll PW, Berman AL, Maris RW, Moscicki EK, Tanney BL, Silverman MM. Beyond the Tower of Babel: A nomenclature for suicidology. Suicide Life Threat Behav 1996; 26(3):237-252.

30. Silverman MM, Berman AL, Sanddal ND, O'Carroll PW, Joiner TE. Rebuilding the Tower of Babel: A Revised Nomeclature for the Study of Suicide and Suicidal Behaviors. Part 1: background, rationale, and methodology. Suicide Life Threat Behav 2007; 37(3):248-263.

31. Silverman MM, Berman AL, Sanddal ND, O'Carroll PW, Joiner TE. Rebuilding the Tower of Babel: A Revised Nomeclature for the Study of Suicide and Suicidal Behaviors. Part 2: Suicide-Related Ideations, Communications, and Behaviors. Suicide Life Threat Behav 2007; 37(3):264-277.

32. Linden $M$, Barrow $S$. The wish to die in very old persons near the end of life: a psychiatric problem? Results from the Berlin Aging Study. Int Psychogeriatr 1997; 9(3):291-307.

33. Lliffe S, Manthorpe J. Screening may not reduce suicide in latter life. Br J Gen Pract 2005; 55(513):261262.

Artigo apresentado em 23/04/2012

Aprovado em 27/06/2012

Versão final apresentada em 19/07/2012 